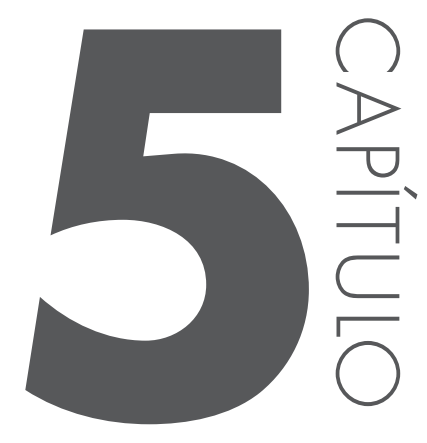

\title{
Conclusão e Recomendações
}

O desenvolvimento econômico sempre esteve relacionado com a preocupação do futuro do país e das pessoas que vivem nele. Contudo, a prioridade de se tomar providências de forma rápida para se manter no poder, levou os governantes brasileiros a pensar somente no crescimento econômico, ou seja, aumentar a produção. Assim, mesmo sendo necessário, pode-se perceber que, na maioria das vezes, foram tomadas medidas e ações paliativas que resolveram parcialmente os seus efeitos, mas jamais as suas causas.

Após o Plano Real, o Brasil conseguiu uma estabilidade econômica e, posteriormente, melhorias na área social, mas falhou ao projetar o planejamento para o futuro, principalmente no que tange a competitividade da indústria nacional, sendo este o setor que mais gera riquezas.

Seleção de Indicadores de Eficiência da Competitividade Industrial Brasileira foi o título desta tese, que, a priori, pode-se argumentar, sob o aspecto dos seus fatores de produção - Terra, Trabalho, Capital, Capacidade Empresarial e Tecnologia - as seguintes conclusões.

No tocante ao fator Terra, fica claro que o Brasil é rico, mas a ineficiência na sua utilização, principalmente com a questão da infraestrutura, é evidente. A ausência de planejamento de longo prazo e de estrutura política frágil, aumenta o "Custo Brasil" e não motiva os empresários a investirem no país, que, na maioria das vezes, buscam o Brasil para investir no mercado financeiro, por ter uma das taxas mais altas do mundo, denominada SELIC (Sistema Especial de Liquidação e Custódia). Quando investem na produção, exigem redução ou isenção de tributos 
e, ainda, mão de obra barata, com salários baixos e, principalmente, não se preocupam em investimentos em Pesquisa, Desenvolvimento e Inovação (P, D \& I).

A mão de obra no país não é valorizada, principalmente na questão do capital intelectual, uma vez que os profissionais formados no ensino superior continuam a ser coadjuvantes na questão de desenvolvimento em inovação tecnológica, ou seja, são usuários e não desenvolvedores da tecnologia que vem de outros países, além de encargos sociais elevados, reforçando a tese de que o Brasil ainda continua sendo um país operário, sendo esse o cenário do fator Trabalho.

No fator de produção Capital (produtivo), o país tem máquinas e equipamentos de última geração, mas não desenvolve praticamente nada, pelo contrário, compra essa tecnologia, tornando mais dependentes da tecnologia externa, corroborando com o fator produtivo Trabalho.

Sobre o quarto fator de produção, Capacidade Empresarial, pode-se considerar que, ema sua grande maioria, os gestores no Brasil são competentes, mas a voracidade em buscar lucros cada vez maiores e atender as exigências de suas matrizes, em especial as empresas com capital estrangeiro, faz com que haja muitas críticas às questões econômicas no país e, por várias vezes, ameaçam o governo com demissões para que sejam atendidos e este, por sua vez, propõe medidas momentâneas e sem eficácia, além de, em alguns casos, protecionistas, como foi o caso do Programa Inovar-Auto, enfatizando mais crescimento econômico do que desenvolvimento econômico. Outros pontos importantes a considerar são os elevados spreads bancários, a alta burocracia e ausência de transparência.

Por último, o fator produtivo Tecnologia, destaca que o país continua sendo um país de produção, mas sem valor agregado. Existem programas e incentivos à $\mathrm{P}, \mathrm{D} \& \mathrm{I}$, mas ainda ineficientes e de difícil acesso, pois não há preocupação com o ensino fundamental. Percebe-se que as empresas incentivam mais cursos técnicos para utilização da tecnologia (operacional), sem necessariamente de conhecimento tecnológico (estratégico), compactuando com as conclusões dos fatores de produção supracitados.

Ao analisar as influências dos fatores da competitividade entre as nações, escolheu-se para essa comparação com o Brasil, os Estados Unidos e a Alemanha, como países desenvolvidos e com potencial tecnológico elevado. A Coreia do Sul, por ser um país que na década de 1950 tinha desempenho econômico e social piores que o Brasil e se transformou em um país desenvolvido por meio da mudança de comportamento e de ações do governo, empresas e famílias, principalmente nos aspectos educacionais e tecnológicos e, por fim, os demais países integrantes do BRICS (Brasil, Rússia, Índia, China e África do Sul), uma vez que por fazer parte desse grupo, é importante verificar o desempenho do Brasil e quais ações devem ser tomadas para buscar a melhor eficiência, potencializando os seus pontos fortes e neutralizar as suas fragilidades. 
Após as análises e comparações dos 12 Pilares da Competitividade Global do Relatório do Fórum Econômico Mundial - WEF (World Economic Forum), dos 10 fatores chave do Mapa Estratégico da Indústria 2013-2022, da CNI (Confederação Nacional da Indústria) e das tendências para o Brasil em 20182019 e 2023-2024, além das tendências para o setor de autopeças em 2019 e 2024, escolhido para exemplificar o setor industrial brasileiro, concluiu-se que os indicadores de eficiência da competitividade industrial brasileira que o país deve agir, de forma imediata, são: infraestrutura e inovação, apoiados com a melhoria na qualidade da Educação.

Além disso, para enfrentar esses desafios, o país necessita de reformas urgentes, tanto políticas quanto tributárias e, inclusive, em P, D \& I. Assim, certamente provocarão mudanças significativas e tornarão o Brasil mais competitivo entre as nações e atrativo para empresários, bem como proporcionarão melhorias na qualidade de vida de sua população e desenvolvimento econômico.

Para isso se tornar uma realidade é fundamental ter seriedade na qualidade da educação e criar programas que aproximem o mundo corporativo do acadêmico, uma vez que no Brasil percebe-se que as empresas exigem profissionais qualificados, mas não acreditam no nosso sistema acadêmico, dificultando informações e dados para criar e desenvolver melhorias de processos e de tecnologia.

Acredita-se que os objetivos desta tese foram cumpridos, uma vez que foram selecionados um conjunto de indicadores de eficiência em comparação com os países industrialmente desenvolvidos, que estimulam a competitividade mais dinâmica e atual do setor industrial brasileiro. Foram discutidos os fatores de produção (Terra, Trabalho, Capital, Capacidade Empresarial e Tecnologia), as relações quanto à eficiência e competitividade do setor industrial brasileiro e as influências dos fatores da competitividade entre as nações, por meio das comparações entre o Brasil, Estados Unidos, Alemanha, Coreia do Sul e os países integrantes do BRICS (Rússia, Índia, China e África do Sul). As análises foram baseadas nos 12 Pilares da Competitividade Global, do Relatório do Fórum Econômico Mundial - WEF (World Economic Forum) e no Mapa Estratégico da Indústria 2013-2022, da CNI (Confederação Nacional da Indústria). Além de analisar, ainda, as principais causas do desequilíbrio entre oferta e demanda do setor industrial, em destaque o setor de autopeças, para exemplificar o seu desempenho no mercado nacional.

A hipótese também foi confirmada, uma vez que, o alto custo dos processos, elevada carga tributária e ausência de uma política industrial mais consistente e atual, restringem os processos da cadeia produtiva do setor industrial e podem levar a problemas de processos e operações como, por exemplo, recursos restritivos da capacidade (Capacity Constrained Resource - CCR), ausências de incentivos em inovação tecnológica, infraestrutura e qualidade na educação, gerando falta 
de qualificação de mão de obra, altos custos logísticos - "Custo Brasil" - e dependência da tecnologia externa, diminuindo a competitividade do Brasil frente aos preços praticados por outros países, como, por exemplo: Alemanha, Estados Unidos, Coreia do Sul, Rússia, Índia, China e África do Sul.

Por fim, acredita-se que o Brasil é um país que tem problemas como os demais, mas se houver mudanças de comportamentos dos agentes econômicos (famílias, empresas nacionais e estrangeiras e do governo), e atuação mais forte das universidades, como aconteceu na Coreia do Sul, na década de 1960, fará do país um exemplo mundial, não somente para estar entre os 10 maiores e melhores países competitivos para aparecer no Relatório de Competitividade Global do WEF, mas também para mostrar melhorias em relatórios sociais, de desenvolvimento humano e ambiental, além de o setor industrial brasileiro melhorar seu desempenho e sua competitividade frente ao mercado internacional. Assim, evitará gargalos futuros no mercado doméstico e, principalmente, tornará o país melhor para se viver, com esperança e certeza de um futuro melhor.

Propostas para trabalhos futuros: após ter analisado os pilares da competitividade das nações e projetar tendências para 2019 e 2024, pretende-se desenvolver para trabalhos futuros a investigação dos itens de infraestrutura que mais afetam o desenvolvimento econômico brasileiro, o chamado "Custo Brasil", com o objetivo de contribuir para o modelo de eficiência da competitividade nacional. 